\title{
Processed food and organic food: A mini review on the safety of public health.
}

\author{
Gaballa Omar* \\ Department of Rhetoric and Composition, The American University in Cairo, Egypt
}

\begin{abstract}
We live in an era where everything is evolving and advancing rapidly. Time is flying by. Fashion styles and movements that lasted for dozens of years now can last up to a couple of months. Every day, new food products flood the markets and are sold in masses; chips, chocolates, candy, sugary products, dairy products, meats, poultry, vegetables, fruits, and every food one can think of. Now-a-days, plant seeds can be genetically engineered to fit the agro-business corporation's and consumer's preferences.
\end{abstract}

Keywords: Organic food, Dairy products, Nutrition, Pesticides.

Accepted on June 30, 2017

\section{Introduction}

We live in an era where everything is evolving and advancing rapidly. Time is flying by. Fashion styles and movements that lasted for dozens of years now can last up to a couple of months. Every day, new food products flood the markets and are sold in masses; chips, chocolates, candy, sugary products, dairy products, meats, poultry, vegetables, fruits, and every food one can think of. Now-a-days, plant seeds can be genetically engineered to fit the agro- business corporations' and consumers' preferences.

While my friends and I were sitting around a bonfire in the middle of the desert near the Wahat Desert Road, enjoying ourselves and filling our stomachs with Coca-Cola and burned marshmallows, discussing the latest World Cup Germany vs. France match, my eyes gazed at the sky, my mind flew away, as I watched the vastness and emptiness of the desert, the tardiness of the passing by clouds that reminded me of the long time any creature or plant needs in order to grow. I started wondering how these delicious treats happen to be that widely available and how these foods are so quickly produced and distributed. I was suddenly knocked out of my daydreaming and inattention to the ongoing conversation by an unexpected stomachache. How dare that ache wake me up from my deep flow of thoughts! The pain became more and more outrageous and I felt the need to go to a medical doctor. My friends drove me to the nearest hospital, half an hour away. What could be the doomed cause of my illness? The weekend was ruined because of my ache. I need to know what spoiled my mood. "What did you eat?" the physician asked [1-3]. Very irritated by the silliness of the question, I answered "Food, I suppose."

Apparently, the delicious foods I was enjoying were the cause of my illness. The doctor prescribed me a medication to disinfect my stomach. How can food be so tricky? I know I caught several illnesses from food before, but the thought never occurred to me till now, that food can be tricky.

As evident as it may seem, food is the substance that keeps us alive. But surprisingly, it can also be the substance that sends us to our graves. According to a study by Paul Mead in the
National Center for Biotechnology Information (NCBI) and to the Center for Disease Control and Prevention (CDCP), more than 5000 deaths due to food-borne diseases occur in the United States alone, left alone that the US is one of the most advanced countries in our world. The food we buy at the supermarkets travels a long way from the farm or factory where it is produced.

Food is processed, stored and handled during every step of its trip to our dinner tables, which makes it vulnerable to viral, bacterial and also fungal contamination. Food-borne diseases and viruses such as E. Coli and Hepatitis A can be deadly. Another very well-known food-borne disease that caused several deaths and made it to the headlines of major newspapers is the "Mad Cow Disease", caused by infected cow meat.

A new kind of food named Organic Food recently invaded the markets, and its producers claim it is safer, tastier, healthier and more nutritious than conventionally processed food. Organic food is food grown without the use of petrochemicals in form of pesticides or fertilizers. Any substance considered as unnatural or not from the farm is excluded from the process. Does this mean the solution to the numerous safety and health problems is found?

In today's scientifically and technologically superior societies, the only types of food available in our markets, processed and organic foods, do not provide effective solutions to the foodrelated public health problems because of the food-borne diseases and fatalities that the industry is apparently unable to prevent from spreading in both the untreated materials (animals, crops) and the consumers.

Health is defined by the World Health Organization as "a state of complete physical, mental and social well-being and not merely the absence of disease or infirmity".

\section{Processed Food}

Food processing is the procedure our food goes through before reaching our dining tables. Harvested crops and slaughtered cattle are processed by a set of techniques and methods through which they are transformed into attractive and marketable food products for humans (or other animals). According to Peter J. 
Fellow's Food Processing Technology Principles and Practice, there are many techniques of processing, such as heat treatment, biochemical treatment, wet or dry treatment, size reduction, packaging and other types. The product handling and trip from the factories until the dinner table are also part of the processing. Food processing has been available for thousands of years, since ancient Greece and Egyptians who used salt to preserve foods and bodies in mummification. The canning, bottling and Pasteurization of food in the nineteenth and twentieth century were the first steps in the modernization of food processing.

These methods lead to a better preservation of food, which explains why they were first developed to serve military personnel, starting with the French Army [4-6].

Now-a-days, food processing has gone far beyond consumers' expectations with the help of the rapidly evolving computer technology and machinery. Similarly as Adam Smith's assembly line mass production method, which Henry Ford used for the early Ford cars models, our food is mass produced, only it is not fitted with parts along the line, but with chemical substances that serve many purposes. On the shelves of supermarkets, any type of food, from powder juices to ready-to-be-served soup, can be found. Food sold in the form of powder can be obtained by many methods; freeze-drying, or spray-drying depending on the substance being dehydrated (some foods may be spoiled using either one of the methods). For example, "instant coffee" is freeze-dried, while milk powder and tea are spray-dried. Food additives such as artificial colorants and flavoring agents (especially sweeteners) manipulate the taste of the food in question and are outstanding advancements for the food industry, as these chemicals help develop new tastes and especially new types of sweets. The packaging and labeling of food products are also key factors of the processing that respectively increases the shelf-life of the product and simplifies the classification of the product for transportation (if it needs an air conditioned container or not) and placement in the supermarkets.

Processing actually increases the safety of the food products because of the packaging that protects it from any possible bacterial or viral contamination, from spoiling because of the weather and it increases the food's shelf-life. Packages sometimes have preservation chemicals inside of them that preserve the quality of the food. Also, the packaging and labeling makes any product more appealing to consumers and might even give them a hint of the taste of the treat it holds. All the additives, whether artificial or not, and whether nutritional (for example: proteins) or non-nutritional, result in an improved taste and a better nutritional value [7-9].

The processing and handling of food is clearly a leap forward for the food industry and for all consumers, because the foods are mass produced and cheaper for everyone. Unfortunately this leap comes at a price; lives are at stake.

The cattle animals of the farm industry and the workers in the barn are both treated rather badly. The workers are exploited and abused; they are usually illegal immigrants that have no rights at all, and the food companies exploit their social and political status by offering them jobs with a very low pay, no insurance, no safety gear and no guarantee for the job. The workers are unskilled, have unsanitary clothing and they harm the animals because they might be disgusted or are forced to do this work which they don't necessarily like, as seen on the documentary Food Inc. The animals in the barns are in huge numbers which doesn't allow them to move. They are not fed food that will make them be healthier, but food that will make them grow bigger than the normal size in a faster time for more profit. The fact that they can't move because of the lack of space and sometimes because their legs cannot support their own weight, makes them unhealthy and vulnerable to diseases and tortured. Imagine if you can't bear your own weight. We cannot be healthy if our food is not healthy.

There has been a noticeable increase of the use of genetically modified seeds around the world because they are cheap. According to a study done by Clive James, published by the ISAAA (International Service for the Acquisition of Agribiotech Applications) "A record 16.7 million farmers, in 29 countries, planted 160 million hectares (395 million acres) in 2011 , a sustained increase of $8 \%$ or 12 million hectares (30 million acres) over 2010." In Hannah Nordhaus' The Beekeeper's Lament, John Miller tells us about the effect of genetically modified (GM) crops on honey and bees; they are one of the factors that are allegedly causing the Colony Collapse Disorder, the honey extracted from these crops is different than the honey from naturally grown crops and the GM seeds modify the mineral composition of the soil, thus affecting the health of the plants. Once again, if our food is not healthy, we cannot be healthy.

The new inventions and the leap in food processing, especially the newly discovered treatment methods and the use of germicides and pesticides affect our food's nutritive value. According to Biology-Online, the nutritional value of a food is "affected by soil and growing conditions, handling and storage, and processing". The Australian government's Better Health Channel also accuses the chemical processing, additives, pesticides, germicides, preservatives, heat treatment, biochemical treatment, wet or dry treatment, size reduction (freeze-drying or spray-drying) of foods, of decreasing the nutritional density, hence the nutritional value of food. This means that our conventionally produced food lacks some of the nutritional value it is supposed to hold [10-13].

The use of pesticides, GM seeds, additives, the chemical processing and all the treatment and handling designed to improve the quality, taste, safety, nutritional value and accessibility of our foods (i.e. low prices) make the foods subject to contamination at any stage or step in the series of processing. There is a high probability that the food will get exposed to a type of pathogen at any time, whether from the atmosphere or the unsanitary handling (hands or storage places) and this affects public health; this is the cause of the yearly 5000 deaths in the US.

\section{Organic Food}

The US Department of Agriculture's National Organic Standards Board defined organic agriculture in April 1995 as "an ecological production management system that promotes and enhances biodiversity, biological cycles and soil biological activity. It is 
based on minimal use of off-farm inputs and on management practices that restore, maintain and enhance ecological harmony." According the US Environmental Protection Agency ""Organically grown" food is food grown and processed using no synthetic fertilizers or pesticides. Pesticides derived from natural sources (e.g., biological pesticides) may also be used in producing organically grown food." Organic food production is legally defined and specific regulations have been determined in order to follow if a farm is to be said organic. Some techniques of organic farming are crop rotation, very limited synthetic chemicals used and the prohibition of GM seeds.

At every step of organic food production, there is no manipulation of nature and the environment as GM crops do. The use of petrochemicals is extremely limited. These facts make the health impact of the grown product on consumers known (unlike the unknown consequences of eating GM food on the long term). The low number of steps in production and processing compared to conventionally produced food makes for a lower probability of food contamination. Thus, organic food might be safer than conventionally processed food. The nutritive value and nutrients that are supposed to be found in organically produced foods are well preserved because of the absence of the biochemical and heat processing. This makes organic food a bit healthier than processed food.

\section{Discussion}

The European Commission estimates an average increase of half a million hectares over the past decade in the area of organic farmland. Currently in the European Union, there are 186000 organic farmlands. It must be noticed that organic foods are flooding the markets and are appearing in television commercials more often. According to a study by Lisa F. Clark, organic food is being globalized. In order to flood the markets, any product must be within a reasonable, affordable price to reach all consumers. In economics, this means the value of the good sold will decrease. It all sounds familiar; mass production all over again. Mass production of organic food endangers the organic farming and production rules. For the price of organic food to be low, a bigger number of foods will have to be grown on the same amount of land area, making for less healthy plants, and hence lower value. The bad health of the plants will encourage firms to enhance it by using antibiotics or other chemicals, which will lead to our conventional processing factories. There will be no difference between organic food and processed food if organic foods are mass produced. So far, they're not mass produced.

Claims that organic food is safer, healthier, more colorful, tastier and overall more appealing than processed food are echoing around the world, especially in social media communities. But I have not been able to back these claims up with any proof or scientific study, as I could not locate any suggesting the supremacy of organic food. The verity that I could not find any such evidence supports my own claim that organic food is no different than normal food; it is just a way for small business owners to compete with big farms and corporations.

Lately, several organic food companies have been involved in economic and financial agreements with big food processors, such as Mondelez (a spin-off from Kraft Foods) and many others (Figure 1).

The giant corporations are taking over the small organic businesses. This means that there is little or no competition between the conventional sector and the organic sector, as the corporations are too powerful for the recently booming organic business.

The non-supremacy of organic foods over processed foods, and the absence of competition with the corporations lead to my claim that organic food might not have health and nutrition at its core and sole goal in the near future, and is just a marketing method to try competing. Also, the number of people dying from food-borne illnesses has not decreased (or been affected) by the spreading of organic food, which means that people are getting sick from organic food and processed food alike.

\section{Role of Medical Doctors and Dietitians}

Food-borne illnesses patients have always sought help from medical doctors that prescribe them chemical medications. Now-a-days, more people are resorting to dietitians.

Dietitians are experts on food matters, nutrition and health who prescribe food and perhaps supplements to patients in order to reach the optimal health. Nutrition Australia identifies qualified dietitians as people who "have undertaken a course of study that has included supervised and assessed professional practice in public health nutrition, medical nutrition therapy and food service management." A nutritionist is an unqualified, uncertified dietitian. She/ He can advise people to eat specific foods, but he cannot clinically help patients.

I think that patients should resort to food instead of medications in case of illness, because it is food that keeps us alive, it builds, strengthens our bodies, our immune system and replenishes them with nutrients after a long active day. "If we think that we're going to go to the doctor and get a pill for everything, then we have messed the whole plan", and "good health makes a lot of sense, but it doesn't make a lot of dollars" in the documentary Food Matters suggest that there might be arrangements of the food industry with the pharmaceutical industry in forming what is called the "Sickness industry". The documentary backs its argument up by stating that 106000 Americans die each year from taking medications exactly as prescribed to heal them from illnesses.

Dietitians or nutritionists might seem like the perfect solution to our food-related public health problems, but this solution is limited by the imperfection of the food that can be prescribed, because the only foods there are to consume are organic and processed foods, which can carry deadly or long term diseases.

\section{Conclusion}

In the end of this research, I think that humans are progressing towards a healthier world, better nourished societies by taking steps and trying to better foods and healing methods; organic food, and dietitians are giant steps in acquiring food as the biggest barrier in front of disease.

Meanwhile, safety and sanitary measures in food processing chains must be implemented on the short term. No workers 


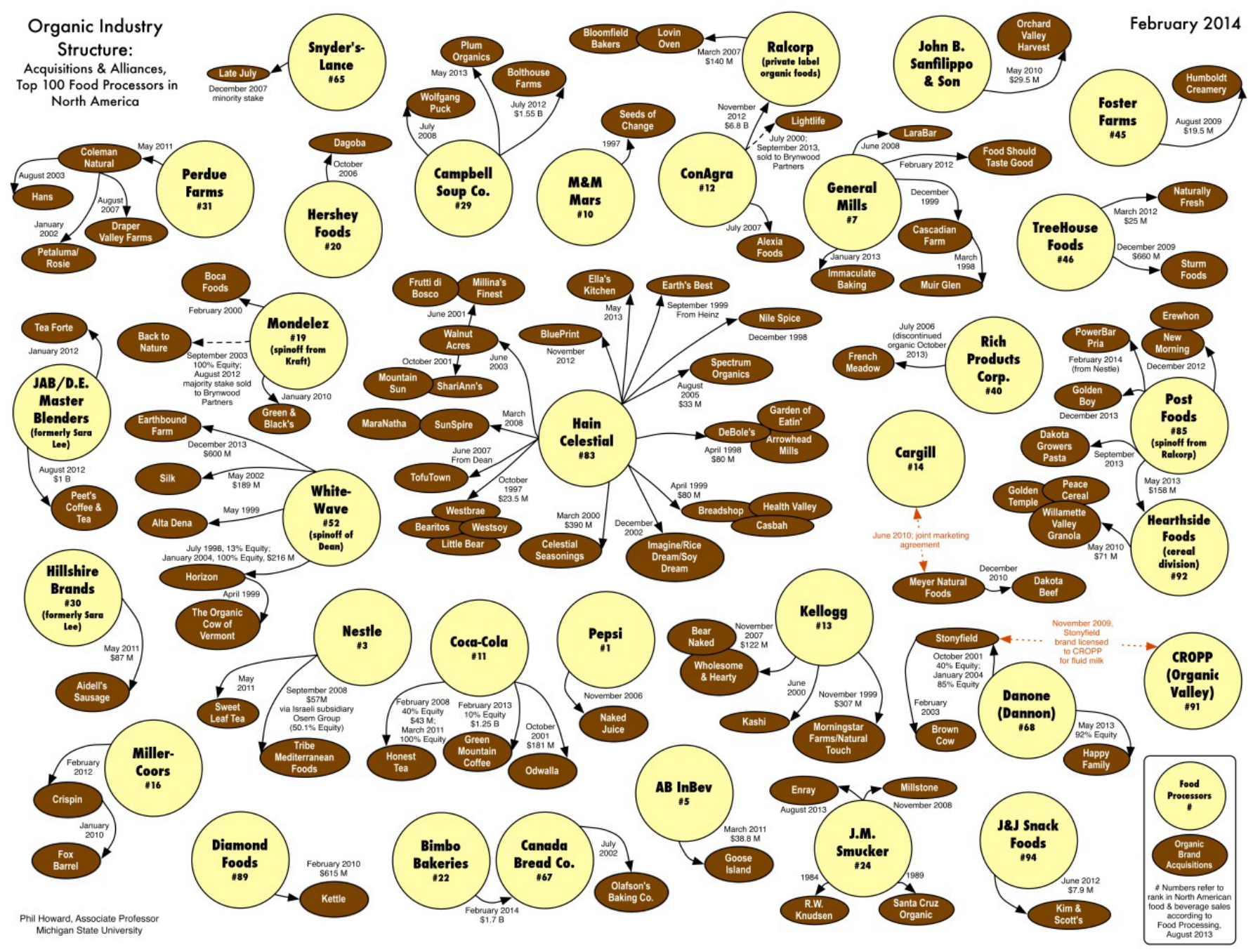

Figure 1. Organic Industry Structure: Acquisitions \& Alliances, Top 100 Food Processors in North America [Image Credits: Phil Howard].

should be exploited, no animals should be abused and no land should be genetically modified to profit companies. Although letting every individual on earth be able to afford food is a noble cause by the food industry and not profit (presumably), the food industry should also emphasize on innovating and inventing newer methods for processing that guarantee a safer, healthier trip for foods instead of inventing machines that make food cheaper. Organic food should not be mass produced. Further investigation and research about this topic are necessary to provide safer and healthier meals for everyone if we as humans are likely to keep going with our contemporary food system. A futuristic solution to our food problems lies in letting a single international and acknowledged non-profit organization whether governmental or not, be in command of the safe production and equal distribution of food around the globe. This entity should be led by delegates of all the countries of the world (similar to the UN), and does not serve the unique purpose of aiding people living in regions of conflict or natural disaster. Each country would specialize in producing some foods. Governments would be forced to dedicate large portions of their budgets to feed their citizens instead of letting the giant multinationals slowly destroy them. Although this solution would prove very costly and extremely difficult to implement, it would create an interdependent world with less conflict. I think that if every small community simply grows its own homemade food, a better planet to live in and healthier people would exist in a shorter time [14-16].

\section{References}

1. Colquhoun DJ. Permacology productions: Food matters. 2008. DVD version.

2. Kenner DR. Alliance Vivafilm, Food, Inc. DVD version.

3. Nordhaus H. Food processing technology: Principles and practice. 2nd ed. Harper Perennial and Peter (eds). The Beekeeper's Lament, Boca Raton: 2011, New York.

4. Mead P. Food-related illness and death in the USA. National Center for Biotechnology Information. U.S. National Library of Medicine, 18th Feb. 2006 (Web. 28th June 2014).

5. Official Records of the World Health Organization. Preamble to the Constitution of the World Health Organization as adopted by the International Health Conference., no. 2, p. 100. Entered into force on 7th April 1948. 
6. Nutritive Value Definition. Biology-Online Dictionary. 2014.

7. Food Processing and Nutrition. Better Health Channel. 29th June 2014.

8. Food Safety and Storage. Better Health Channel. 29th June 2014.

9. Clark L. Globalization, corporatization and the organic philosophy: Social sustainability in question. Progressive Economics Forum, 30th June 2014.

10. Food Safety Facts. Centers for Disease Control and Prevention. Centers for Disease Control and Prevention. 24th Sept. 2012. (Web. 7th July 2014).

11. James, C. Global Status of Commercialized Biotech/GM Crops: 2011. International Service for the Acquisition of Agri-biotech Applications. International Service for the Acquisition of Agri-Biotech Applications, 1st Jan. 2011. Web. 9th July 2014.
12. Pesticides and Food: What organically grown means. EPA. Environmental Protection Agency, Web. 9th July 2014.

13. Organic Production and Organic Food: Information Access Tools. National Agricultural Library. 10th July 2014.

14. What is organic farming? - Organic Farming. European Commission. 10th July 2014.

15. Howard P. Organic Industry Structure: Acquisitions and Alliances, Top 100 Food Processors in North America. Cornucopia Institute RSS. The Cornucopia Institute. 11th July 2014.

16. Nutritionist or Dietitian. Welcome to Nutrition Australia. Nutrition in Australia. 11th July 2014.

\section{*Correspondence to:}

Gaballa Omar

Department of Rhetoric and Composition

The American University in Cairo

Egypt

Tel no: +20 226153471

E-mail: omarica7@aucegypt.edu 